\title{
PERFIL CRIATIVO DOCENTE-DISCENTE: INFLUÊNCIANO ENSINO, HABILIDADES E ATITUDES DA ENFERMAGEM
}

Onã Silva, Elioenai Dornelles Alves², Maria Cristina Soares Rodrigues ${ }^{3}$

Objetivo: analisar o perfil criativo de docentes e discentes do ensino superior de Enfermagem e discutir sua influência no cuidar. Metodologia: estudo exploratório-descritivo desenvolvido em dois Cursos de Graduação de Enfermagem, Distrito Federal, com 251 estudantes e 26 docentes, distribuídos em 4 grupos. Enquadramento conceitual oriundo de Teorias da Criatividade. Coletaram-se os dados, aplicando questionário validado contendo características do perfil criativo. Realizaram-se estatísticas de frequência absoluta e relativa. Resultados: curiosidade, espontaneidade, coragem e Persistência foram características do perfil criativo mais destacadas. Tais aspectos de pensamento e atitudes são indispensáveis aos profissionais atuantes na cultura dos cuidados. Conclusão: o ensino promotor da expressão criativa docente-discente desenvolve potenciais, habilidades e atitudes cuidativas.

Descritores: Enfermagem, Educação Superior, Criatividade, Aprendizagem, Habilidade.

\section{TEACHER-STUDENT CREATIVE PROFILE: INFLUENCE IN NURSING TEACHING, SKILLS AND ATTITUDES}

Objective: to analyze the creative profile of higher education nursing teachers and students and discuss its influence in health care. Methodology: this is a descriptive-exploratory study developed in two Nursing Undergraduate Courses, Federal District, whose guiding question was: what are the creative characteristics declared by higher education nursing teachers and students? Its conceptual framework arises from Theories of Creativity. Data were collected by applying a validated questionnaire containing profile creative characteristics. Statistics of absolute and relative frequency were conducted. Results: Curiosity, Spontaneity, Courage and Persistence were the most highlighted characteristics of the creative profile. Such aspects of thought and attituds are indispensable to professionals working in the culture of care. Conclusion: the teaching that promotes the teacher-student creative expression develops strengths, skills and attitudes toward health care.

Descriptors: Nursing, Higher Education, Creativity, Learning, Aptitude.

\section{PERFIL CREATIVO ENSEÑANTE-ESTUDIANTE: INFLUENCIA EN LA ENSEÑANZA, HABILIDADES Y ACTITUDES DE LA ENFERMERÍA}

Objetivo: analizar el perfil creativo de los enseñantes y estudiantes de la enseñanza superior de enfermería y discutir su influencia en la atención. Metodología: estudio exploratorio-descriptivo desarrollado en dos Cursos de Pregrado de Enfermería, Distrito Federal, cuya pregunta orientadora fue: ¿cuáles son las características creativas declaradas por los enseñantes y estudiantes del curso superior de enfermería? Encuadre conceptual procedente de las Teorías de la Creatividad. Los datos fueron recogidos mediante la aplicación de un cuestionario validado conteniendo las características del perfil creativo. Se realizaron estadísticas de frecuencia absoluta y relativa. Resultados: Curiosidad, Espontaneidad, Coraje y Persistencia fueron las características del perfil creativo más destacadas. Estos aspectos del pensamiento y actitudes son indispensables para los profesionales que trabajan en el cuidado de la atención. Conclusión: la enseñanza promotora de la expresión creativa enseñante-estudiante desarrolla los potenciales, habilidades y actitudes de atención. Descriptores: Enfermería, Educación Superior, Creatividad, Aprendizaje, Aptitud.

1Enfermeira. Doutora. Secretaria de Saúde do Distrito Federal, Brasilia, DF. Brasil. E-mail: onatil.silva@gmail.com

${ }^{2}$ Enfermeiro (in memoriam). Doutor. Programa de Pós-Graduação em Enfermagem, Universidade de Brasilia (UNB), Brasilia, DF, Brasil. ${ }^{3}$ Enfermeira. Doutora. Professora Associada, Faculdade de Ciências da Saúde, UnB, Brasilia, DF, Brasil. 


\section{INTRODUÇÃO}

Qual a importância de investigar a criatividade no ensino superior de Enfermagem analisando as características criativas dos professores e alunos deste campo do saber? Em que medida tais aspectos investigados no ensino de Enfermagem influenciam os cuidados à saúde humana?

Estas inquietações e questionamentos advêm de estudos da la autora - especificamente na temática da Tese - e fruto de estudos relacionados ao problema que tem comprometido o ensino de Enfermagem: ênfase no processo ensinoaprendizagem tecnicista, que dista dos aspectos múltiplos inerentes às pessoas e à cultura dos cuidados.

\section{A personalidade criativa, o pensamento criativo e as dimensões da complexidade}

Pesquisas sobre a personalidade e pensamento criativo estão no temário científico. Quanto às características criativas - dentre os referenciais pioneiros ${ }^{(1)}$-, destacamse a flexibilidade cognitiva, persistência e dedicação laboral, pensamento independente, abertura às experiências e aos interesses inusitados. Ressaltam-se outras fontes ${ }^{(2-4)}$ que identificaram características como intuição, espontaneidade, fluência, originalidade e outros aspectos associados às habilidades, como temperamento, interesses e atitudes.

Posteriormente, no que tange à personalidade criativa, outro teórico(5) apresentou as definições de pessoa brilhante - possui pensamentos inusitados e estimulantes -; a personalidade criativa - possui percepção tranquila e cheias de insight -; e a pessoa criativa possui criações históricas. O teórico definiu criatividade como a interação entre domínio, área e pessoa, e resultado de oportunidade versus perseverança; somando aos traços da expressão criativa, como a predisposição genética, o interesse e o acesso ao domínio. Para o teorista, existe uma grande aura de complexidade criativa, inclusive muitas vezes oposta, que envolve as pessoas de energia psíquica intensa para trabalhar durante horas; inteligência e simplicidade; brincadeira e disciplina; introversão e extroversão; ambição e altruísmo; competição e cooperação e outras características.

Considerando o breve referencial temático deste introito, a expressão criativa é uma singularidade humana que, em condições ideais, manifesta-se plenamente, sendo fundamental desde a formação ao ato de cuidar.

\section{A criatividade no ensino superior de Enfermagem}

Raros estudos têm investigado o fenômeno criatividade no contexto universitário. Dentre os publicados ${ }^{(6,7)}$, os mesmos são referenciais históricos pelas contribuições ao processo ensinar-aprender. É importante realçar a seguinte reflexão, real desde a publicação: “Apesar da importância da educação superior para o fomento da criatividade, constatase que pouca atenção tem sido dada ao desenvolvimento das habilidades criativas do estudante neste nivel de ensino (6:203).

Quanto ao saber-enfermagem, o ensino - inclusive de nivel superior - tende ao tecnicismo, à fragmentação do saber com sérias implicações à formação criativa, reflexiva e crítica - infelizmente, modelo hegemônico ao longo da história(8-11).

$O$ ensino de Enfermagem requer aspectos criativos no currículo, pois: "A área do saber-enfermagem tem realizado ações cuidativas que solicitam desenvolvimento de competências, habilidades e atitudes criativas, multidisciplinares e lúdicas do profissional de Enfermagem, contribuindo sobremaneira na produção do conhecimento estético - ciência ainda em processo de construção"(9:18).

Na construção da ciência de Enfermagem, os estudos no temário criatividade e sua influência no ensino, habilidades e atitudes, são relevantes. Por isso, os autores envidaram esforços nesta pesquisa, definindo como questão norteadora: quais as características criativas declaradas por professores e estudantes de curso superior de Enfermagem? Elaborouse como objetivo: analisar o perfil criativo de docentes e discentes do ensino superior de Enfermagem e discutir sua influência no cuidar.

\section{METODOLOGIA}

Delineou-se uma pesquisa de natureza exploratóriadescritiva, realizada entre 2013 e 2014. Referente ao enquadramento conceitual, recorreu-se à Teoria Sistêmica da Criatividade(5), Teoria Geral para o Desenvolvimento da Produtividade Criativa em Jovens ${ }^{(12)}$ e à Teoria da Complexidade ${ }^{(13)}$.

\section{Critérios para seleção das instituições e participantes da pesquisa \\ Conforme descrito em 2015, no Relatório do Conselho} Federal de Enfermagem (Cofen), no Distrito Federal, encontravam-se ativos 22 cursos de bacharelado em Enfermagem presenciais, segundo dados extraídos do Censo da Educação Superior no Brasil, 2013 ${ }^{(14)}$. A maioria dos cursos oferta ensino particular e três oferecem ensino público - dois ligados à instituição federal, porém em campi distintos -, e o terceiro, vinculado ao Governo do Distrito Federal.

Quanto aos contextos, os cursos superiores de Enfermagem deste estudo foram assim identificados: o Cenário de Ensino 1, Campus Central da instituição pública federal; e o Cenário de Ensino 2, Campus de instituição particular.

Concernente aos partícipes, formaram-se grupos nos Cursos de Graduação em Enfermagem eleitos: no Cenário de Ensino 1, o Grupo docente Alegrar (A) e o Grupo discente 
Brincar (B); no Cenário de Ensino 2, o Grupo docente Colorir (C) e o Grupo discente Divertir (D). Optou-se pelas denominações aos grupos, em alusão aos verbos de ação relacionados ao processo ensino-aprendizagem que envolve a criatividade.

\section{Critérios de inclusão e exclusão dos participantes da pesquisa}

$\mathrm{Na}$ inclusão, os participantes constituíram-se de atores educacionais vinculados aos Cenários 1 e 2 - docentes em exercício e estudantes matriculados -, e que aceitaram o convite da pesquisa, assinando o Termo de Consentimento Livre e Esclarecido (TCLE).

Como exclusão, docentes de outras instituições e de outras áreas não participaram. Excluíram-se estudantes quem se encontravam nas situações de matrícula trancada, transferência ou abandono de curso.

\section{Instrumentos}

$\mathrm{Na}$ pesquisa geral, utilizou-se como técnica de coleta de dados aos grupos - discentes e docentes - o preenchimento de questionários consagrados e validados em pesquisas na temática sobre criatividade no ensino(7). Para fins operacionais, trabalharam-se com Anexos distintos, organizando-os em Cadernos de Pesquisa, distintos pela cor: Caderno Azul (Grupo A) e Caderno Verde (Grupo B), destinados aos professores e alunos do ensino público; Caderno Amarelo (Grupo C) e Caderno Lilás (Grupo D), aos professores e alunos do ensino privado.

Originalmente, os Cadernosapresentamtrês instrumentos de pesquisa validados na temática- Questionário de Avaliação de Procedimentos Docentes, Escala de Avaliação do Nível de Criatividade, Inventário de Barreiras à Criatividade Pessoal(7) - incorporando-se um quarto instrumento, o Questionário das Características do Perfil Criativo (OCPC), aqui analisado. O formato do OCPC foi idêntico aos grupos, sendo permitido marcar mais de uma dessas características: resistência à frustração, coragem, persistência, intuição, ideias divergentes, ideias inusitadas, independência, simpatia, autoconfiança, espontaneidade, gosto pela aventura, curiosidade, fantasia e outras.

Coletaram-se também dados complementares dos professores - as variáveis foram sexo, idade, estado civil, titulação e carga horária de trabalho - e dos alunos foram sexo, idade e trabalho.

Os dados coletados, armazenados originalmente nos cadernos de pesquisa, foram digitados em planilha do Microsoft Excel; posteriormente, estudados e submetidos a tratamento estatístico, extraindo as frequências absolutas e percentuais.
Esta pesquisa foi aprovada pelo Comitê de Ética em Pesquisa, da Faculdade de Ciências da Saúde, Universidade de Brasilia (UnB), conforme o Parecer no 378.540/2013, e atende aos preceitos da Resolução no 466/2012(15).

\section{RESULTADOS}

Participaram do estudo 277 pessoas, conforme a seguinte distribuição, por Grupo específico: Alegrar (A), formado por 18 docentes; Brincar (B), por 136 estudantes; Colorir (C), por oito docentes; e o Divertir (D), por 115 estudantes.

Quanto aos resultados sociodemográficos, referentes ao sexo, na amostra docente (Grupo Alegrar-A) houve predominância feminina ( $n=16 ; 88,9 \%)$; enquanto que, no Grupo Colorir (C), mais partícipes masculinos ( $n=6,75 \%)$. Quanto aos discentes, predominaram estudantes femininos: Grupo Brincar-B (n=132; 97,1\%) e Grupo Divertir-D (n=100; $87 \%$ ). Sobre o estado civil, metade do Grupo A ( $n=9 ; 50 \%)$ informou ser casado; e no Grupo C, cinco docentes (62,5\%) solteiros. Quase a totalidade dos discentes se declarou solteira: Grupo B ( $n=124 ; 91,2 \%)$ e Grupo D ( $n=87 ; 75,7 \%)$. Segundo a faixa etária docente, no Grupo A, oito (44,4\%) têm mais de 51 , e seis no Grupo C (75\%) têm menos de 35 anos. A faixa etária discente concentrou-se em menores de 18 a 20 anos - Grupo B ( $n=66 ; 48,5 \%)$ e Grupo D ( $n=45 ; 40,2 \%)$-; seguida daqueles com 2l-25 anos, Grupo B ( $n=58 ; 42,6 \%)$ e Grupo D (n=24, 21,4\%).

Relativo à titulação dos docentes, no Grupo Alegrar (A), a maioria ( $\mathrm{n}=11$; 61,1\%) possuía Doutorado e no Colorir (C) Especialização ( $n=5 ; 62,5 \%)$. Nos dados trabalhistas, no Grupo A, predominaram docentes em dedicação exclusiva (DE), e no Grupo C, respondentes com mais de um vínculo. Quanto aos discentes, em ambos os grupos, a maioria informou não trabalhar.

$\mathrm{Na}$ Figura 1, encontram-se as características de pensamento e ação das pessoas criativas. Os respondentes marcaram as opções, declarando as próprias características criativas - foi possivel marcar tantas opções quantas fossem os traços criativos autodeclarados.

Figura 1 - Lista de características do perfil criativo aos Grupos A, B, C e D dos Cursos de Graduação em Enfermagem

Qual(is) a(s) característica(s) de perfil criativo que você considera que
possui:
$\begin{array}{lll}\text { ( ) resistência a frustração } & (\text { ) coragem } & \text { ( ) persistência } \\ \text { ( ) intuição } & (\text { ) ideias divergentes } & (\text { ) ideias inusitadas } \\ \text { ( ) independência } & (\text { ) simpatia } & (\text { ) autoconfiança } \\ \text { ( ) espontaneidade } & (\text { ) gosto pela aventura } & (\text { ) curiosidade } \\ \text { ( ) fantasia } & (\text { ) outras }\end{array}$

Fonte: oriunda da pesquisa

Na Tabela 1, estão dispostos os resultados sobre as características criativas, em frequência absoluta e 
percentual. Identificaram-se, no Grupo A, as características mais autodeclaradas, em ordem percentual decrescente: Curiosidade, Espontaneidade, Coragem, Persistência, Intuição, Autoconfiança e Independência. Os discentes do Grupo B autodeclararam em ordem decrescente percentual: Curiosidade, Espontaneidade, Persistência e Simpatia. No Grupo C, Espontaneidade foi a mais marcada, seguida de Autoconfiança, Coragem, Ideias Inusitadas, Intuição. Observa-se no Grupo D apenas a característica Curiosidade com percentual de $67 \%$, sendo os demais itens abaixo de $50 \%$.

Tabela 1 - Características do perfil criativo, nos Grupos A, B, C e D, dos Cursos de Graduação em Enfermagem, Brasília, DF, Brasil, 2014

\begin{tabular}{|c|c|c|c|c|c|c|c|c|}
\hline \multirow{3}{*}{$\begin{array}{l}\text { Características } \\
\text { do Perfil Criativo }\end{array}$} & \multicolumn{8}{|c|}{ GRUPOS } \\
\hline & \multicolumn{2}{|c|}{$\begin{array}{c}\text { ALEGRAR } \\
\text { A }\end{array}$} & \multicolumn{2}{|c|}{$\begin{array}{c}\text { BRINCAR } \\
\text { B }\end{array}$} & \multicolumn{2}{|c|}{$\begin{array}{c}\text { COLORIR } \\
\text { C }\end{array}$} & \multicolumn{2}{|c|}{$\begin{array}{c}\text { DIVERTIR } \\
\text { D }\end{array}$} \\
\hline & $N$ & $\%$ & $\mathrm{~N}$ & $\%$ & $N$ & $\%$ & $\mathrm{~N}$ & $\%$ \\
\hline Curiosidade & 14 & 77,8 & 104 & 77,6 & 6 & 75,0 & 77 & 67,0 \\
\hline $\begin{array}{l}\text { Resistência à } \\
\text { frustração }\end{array}$ & 2 & 11,1 & 32 & 23,9 & 1 & 12,5 & 26 & 22,6 \\
\hline Autoconfiança & 10 & 55,6 & 48 & 35,8 & 6 & 75,0 & 40 & 34,8 \\
\hline Coragem & 12 & 66,7 & 45 & 33,6 & 6 & 75,0 & 57 & 49,6 \\
\hline $\begin{array}{l}\text { Espontanei- } \\
\text { dade }\end{array}$ & 14 & 77,8 & 82 & 61,2 & 7 & 87,5 & 53 & 46,1 \\
\hline Fantasia & 4 & 22,2 & 30 & 22,4 & 2 & 25,0 & 25 & 21,7 \\
\hline $\begin{array}{l}\text { Gosto pela } \\
\text { aventura }\end{array}$ & 4 & 22,2 & 36 & 26,9 & 3 & 37,5 & 27 & 23,5 \\
\hline $\begin{array}{l}\text { Ideias } \\
\text { divergentes }\end{array}$ & 6 & 33,3 & 41 & 30,6 & - & - & 31 & 27,0 \\
\hline $\begin{array}{l}\text { Ideias } \\
\text { inusitadas }\end{array}$ & 8 & 44,4 & 43 & 32,1 & 5 & 62,5 & 27 & 23,5 \\
\hline Independência & 9 & 50,0 & 62 & 46,3 & 3 & 37,5 & 44 & 38,3 \\
\hline Intuição & 10 & 55,6 & 65 & 48,5 & 5 & 62,5 & 41 & 35,7 \\
\hline Persistência & 11 & 61,1 & 79 & 59,0 & 2 & 25,0 & 51 & 44,3 \\
\hline Simpatia & 6 & 33,3 & 79 & 59,0 & 4 & 50,0 & 45 & 39,1 \\
\hline Total & 18 & $100 \%$ & 134 & $100 \%$ & 8 & $100 \%$ & 115 & $100 \%$ \\
\hline
\end{tabular}

$\mathrm{Na}$ Figura 2, visualizam-se os resultados individuais e comparativos das características do perfil criativo. $\mathrm{Na}$ representação gráfica, o eixo y (plano vertical) refere-se às características e o eixo x (plano horizontal) aos resultados percentuais. Destacaram-se Curiosidade, Espontaneidade, Coragem e Persistência.

Comparativamente, foram menos autodeclaradas as seguintes características, em todos os Grupos: Fantasia,
Gosto pela aventura e Resistência à Frustração. Nota-se que o Grupo C destaca-se em quase todas as características, comparado aos outros Grupos, excetuando Independência, Persistência, Resistência à Frustração. Curiosidade foi uma característica com representação gráfica quase similar entre os Grupos, com discreta diferença para menos, no Grupo D.

Figura 2 - Características do perfil criativo, nos Grupos A, B, C e D, dos Cursos de Graduação em Enfermagem, Brasília, DF, Brasil, 2014

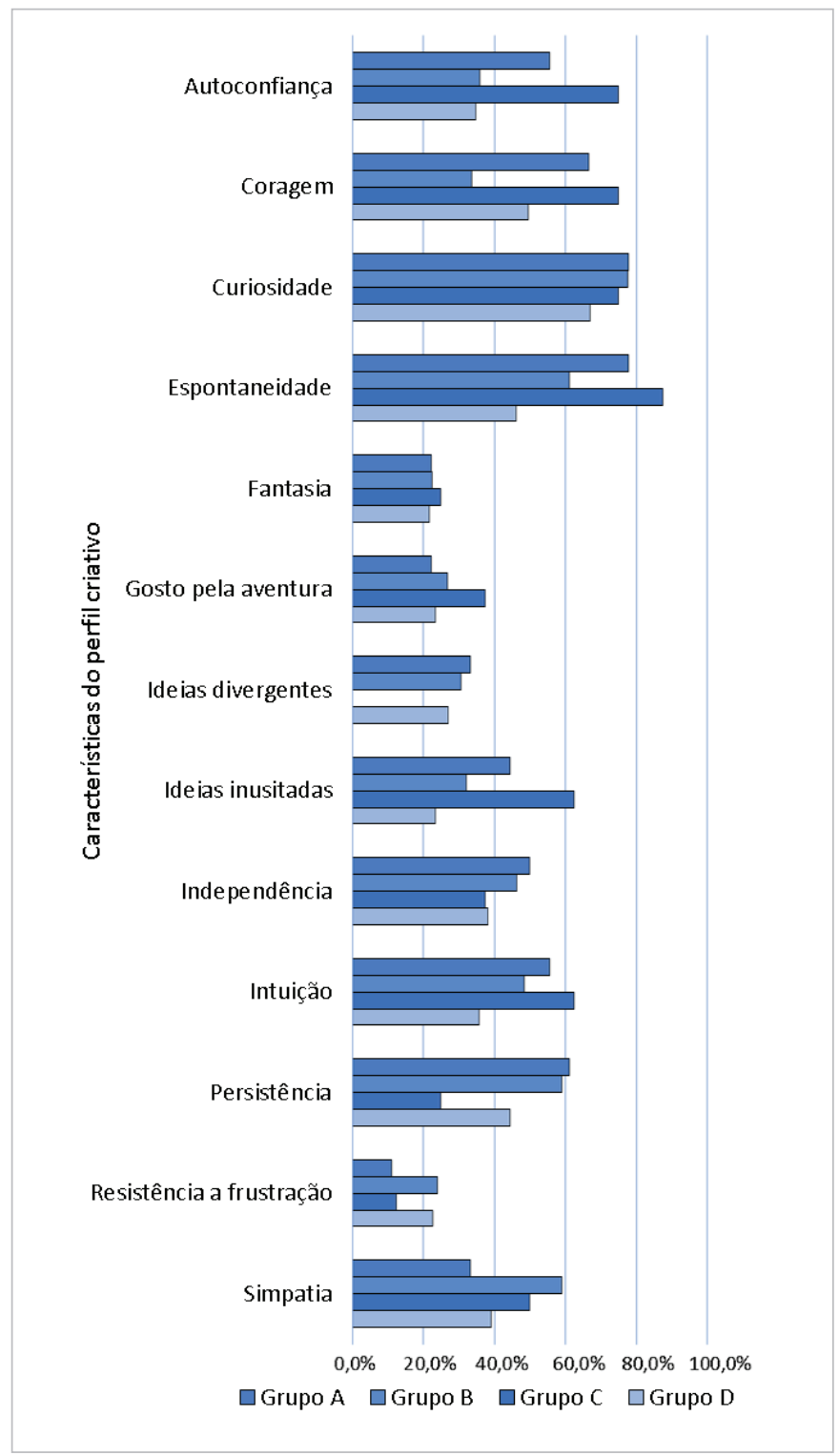

Fonte: oriunda da pesquisa

\section{DISCUSSÃO}

As características do perfil criativo evidenciadas no estudo corroboram com os dados na temática ${ }^{(1-7)}$, sintonizadas aos pressupostos teóricos da visão sistêmica e complexidade humana $^{(5,12,13)}$.

Quanto ao perfil criativo, os partícipes autodeclararam Curiosidade, Espontaneidade, Coragem e Persistência 
mais relacionadas às suas personalidades. Tais aspectos de pensamento e atitudes são indispensáveis aos profissionais atuantes na cultura dos cuidados. Ou seja, as ações cuidativas integrais solicitam profissionais com perfil criativo - pois o cuidado acontece como momento único, irrepetivel e dinâmico, nos espaços de cuidar ${ }^{(8)}$. As características mais autodeclaradas são valiosas na atuação docente, discente e profissional de Enfermagem.

Cotejando os resultados ao objeto deste estudo, as características identificadas no perfil docente-discente, são contributos ao ensino criativo, troca de saberes, práticas, conhecimentos e exercício de enfermagem inovador ${ }^{(9-11)}$. Os resultados permitem a interconexão ao enquadramento teórico sobre criatividade, suporte a esta investigação(5,12,13).

A criatividade, ao ser expressa e desenvolvida no ensino, é uma força revitalizadora para o autocuidado e do outro, favorece também o autoconceito e expressão criativa $^{(9-11)}$; por isso, as caracteristicas identificadas - Curiosidade, Espontaneidade, Coragem e Persistência - são essenciais no ensino, na aprendizagem e nos cenários cuidativos.

No ensino superior de Enfermagem, identificar características do perfil criativo docente-discente pode contribuir na formação, pela sintonia aos preceitos das Diretrizes Curriculares Nacionais para o Ensino de Enfermagem (DCN-Enf)(16), que destaca o potencial criativo, visando aprendizagem, habilidades e atitudes dos seus atores.

Estudos concluiram ${ }^{(5-7,9-11,17)}$ que as pessoas tornam-se mais criativas, influenciadas por experiências educacionais com ambiência ideal para promoção de expressividades e desenvolvimento do perfil criativo.

Nestes cenários formativos - do cuidar e para o cuidar -, a base é o lidar com a subjetividade - emoções, dores, amores, alegrias, tristezas, saúde, doenças e outras situações -, sendo, portanto, o nascedouro do fluxo criativo e revitalizador das ações cuidativas $^{(11,16)}$. São cenários para a revitalização educacional advindas das características criativas, influenciadoras na aprendizagem, no ensinar-aprender e no processo de cuidar.

\section{CONCLUSÃO}

No campo-saber Enfermagem, o modelo tradicional vem impedindo expressividades e potenciais criativos. No ambiente formador, lócus do ensino, aprendizagens, práticas, experiências, saberes e pesquisas relacionadas à cultura cuidativa estão os atores educacionais - professores, estudantes, gestores -, cuja percepção de si mesmos contribui ao ensino de Enfermagem de base inovadora e criativa.

Os atores educacionais que se reconhecem criativos contribuirão para as rupturas do tecnicismo, pois emergirão atuações docentes e discentes com inovação, criação, recriação -, cujas ideias, habilidades e atitudes serão frutos das características do perfil criativo docente-discente.

Decorrente de tema inédito, acredita-se que os resultados deste estudo são relevantes, ao apresentar dados, resultados, reflexões e saberes em prol da arte da Enfermagem. A esperança é que este estudo seja um referencial e contributo na cultura dos cuidados.

\section{REFERÊNCIAS}

1. Mackinnon DW. Identifying and developing creativity. In: Gowan JC Demos GD, Torrance EP (editors). Creativity. Its educational implications. New York: Wiley; 1967.

2. Barron F. Creative person and creative process. New York: Holt, Rinehart \& Winston; 1969.

3. Guilford JP. The nature oh human intelligence. New York: McGrawHill: 1967.

4. Guilford JP. Factors that aid and hinder creativity. In: Gowan JP, Demos GD, Torrance EP (editors). Creativity. Its educational implications. New York: Wiley: 1967.

5. Csikszentmihalyi M. Creativity: Flow and the psychology of discover and invention. New York: Perennial; 2013.

6. Alencar EMLS, Fleith DS. Criatividade na educação superior: fatores inibidores. Avaliação. 2010, 15(2): 201-6.

7. Alencar EMLS, Bruno-Faria, MF, Fleith DS. Medidas de Criatividade. Porto Alegre: Artmed; 2010.

8. Silva O. Projeto Cuidarte: o ensino do curso de graduação em enfermagem revitalizado pela criatividade e arte. In: VII Congresso Iberoamericano de Docência Universitária. Ensino Superior: Inovação e Qualidade na Docência: Livro de Atas; 24 a 27 jun 2012: Porto, Portugal.1055-56.

9. Silva $\mathrm{O}$. A enfermagem nas ondas da criatividade e ludicidade: relato de experiência. In: Sá AVM, Silva AJN, Braga MD, Silva O. Ludicidade e suas interfaces. Brasilia (DF): Editora Liber Livro Ltda; 2013. p. 17-38.

10. Silva O, Alves ED, Rodrigues MCS. Liricidad y toque de arte para la producción del conocimiento estético de enfermeria - una reflexión poética inspirada en la Teoría de la Complejidad. Cultura de los Cuidados [internet]. 2014. [Acessado em 15 jun 2015]; 18(39):14-29. Disponivel em:

http://dx.doi.org/10.7184/cuid.2014.39.03

11. Silva O. As ondas revitalizadoras da criatividade no ensino superior de Enfermagem - estudo comparativo e multifatorial do perfil criativo dos atores educacionais [tese na internet]. Brasilia (DF): Programa de PósGraduação em Enfermagem da Universidade de Brasilia, Brasilia; 2015 [acesso em: 18 nov 2015]. 296 p. Disponivel em: http://repositorio.unb.br/ handle/10482/18227

12. Renzulli JS. A general theory for the development of creative productivity in young people. In: Mönks FJ, Peters W (editors), Talent for the future (pp.51-72). Assen Maastricht, The Netherlands: Van Gorcum; 1992.

13. Morin E. Introdução ao pensamento complexo. Porto Alegre: Sulina; 2015

14. Conselho Federal de Enfermagem (Cofen). Relatório consubstanciado da operação EAD Cursos de Graduação em Enfermagem em resposta ao MPF. Brasilia; 2015 [acesso em: 18 fev 2016]. 17p. Disponivel em: http:// repositorio.unb.br/handle/10482/18227

http://www.cofen.gov.br/wp-content/uploads/2015/11/RELATORIO_ CONSUBSTANCIADO.pdf

15. Ministério da Saúde (BR). Resolução 466 de 12 de dezembro de 2012: Diretrizes e normas regulamentadoras da pesquisa envolvendo seres humanos. Brasilia, 2012.

16. Brasil. Resolução CNE/CES 3/2001. Dispõe sobre as Diretrizes Curriculares Nacionais do Curso de Graduação em Enfermagem. Diário Oficial da União, Brasilia, 9 de Novembro de 2001. Seção 1, p. 37.

17. Gomes ARM, Vasconcelos HCA, Silva O. Criatividade: opinião de alunos e professores sobre a utilização dessa competência na formação de enfermeiros. Revista de Enfermagem Ufpe On Line [internet]. 2015 [acesso em: 21 jan 2016]; 9(3):7599-608. Disponivel em: http://www.revista.ufpe.br/ revistaenfermagem/index.php/revista/article/view/6348 